\title{
The Effect of Reinforcement Volume Ratio on Porosity and Thermal Conductivity in Al-Mgo Composites
}

\author{
Recep Calin, Muharrem Pul*, Zühtï Onur Pehlivanli \\ Department of Metallurgical and Materials Engineering, Kirlkkale University, Kırlkkale, Turkey
}

Received: January 21, 2012; Revised: August 1, 2012

\begin{abstract}
In this study, the effects of reinforcement volume ratios (RVR) on composite structure and thermal conductivity were examined in $\mathrm{Al}-\mathrm{MgO}$ reinforced metal matrix composites (MMCs) of 5\%, $10 \%$ and $15 \%$ RVR produced by melt stirring. In the production of composites, EN AW 1050A aluminum alloy was used as the matrix material and $\mathrm{MgO}$ powders with particle size of $-105 \mu \mathrm{m}$ were used as the reinforcement material. For every composite specimen was produced at $500 \mathrm{rev} / \mathrm{min}$ stirring speed, at $750{ }^{\circ} \mathrm{C}$ liquid matrix temperature and 4 minutes stirring time. Composite samples were cooled under normal atmosphere. Then, microstructures of the samples were determined and evaluated by using Scanning Electron Microscope (SEM) and Energy Dispersive X-ray Spectroscopy (EDS) analysis. In general, it was observed that the reinforcement exhibited a homogeneous distribution. Furthermore, it was determined that the increase in the RVR increased porosity. From the Scanning Electron Microscope images, a thermal Ansys model was generated to determine effective thermal conductivity. Effective thermal conductivity of $\mathrm{Al}-\mathrm{MgO}$ composites increased with the decrease in reinforcement volume ratio.
\end{abstract}

Keywords: metal-matrix composites, melt stirring, microstructure, porosity, thermal conductivity

\section{Introduction}

Development of technology and increasing demands of industry have lead to an increase in research and development studies on the production of composites with different properties in recent years. This increase is attributed to the high strength of composite materials with low specific weight. Additionally, due to the possibility of their production in different combinations with desired strength levels and their high fatigue resistance, toughness, high temperature strength as well as high oxidation and wear resistances contributed in the increased utilization of composites ${ }^{1}$.

There are many different composite materials and production types which are further growing. Metal Matrix Composites (MMCs) is one of these composite materials. All engineering materials can be used as matrix for the production of MMCs. Aluminium, magnesium and their alloys are the most commonly used matrix materials in the production of MMCs due to their lightness and ductility. Materials like $\mathrm{SiC}, \mathrm{SiO}_{2}, \mathrm{Al}_{2} \mathrm{O}_{3}$ and $\mathrm{MgO}$ are generally preferred as reinforcement elements. In the production of MMCs, different methods such as casting, melt stirring, powder metallurgy, in-situ and infiltration are used. Melt stirring method has a good potential in all-purpose applications as it is a low cost MMCs production method ${ }^{2}$. To obtain a successful reinforcement process in the production of MMCs, the most important and effective criterion is the selection of the appropriate method and material as reported by the literature. Furthermore, in MMCs production with

*e-mail: mpul@gazi.edu.tr; muharrempul@hotmail.com melt stirring method, increased Reinforcement Volume Ratio (RVR) and decreased particle size resulted more difficult production process and increased porosity and particle agglomeration $^{3,4}$.

Many studies have been conducted on the distribution of reinforcement elements inside the composites and their effect on microstructure, porosity, hardness, abrasion behavior and rupture strength as well as the effect of stirring time and speed ${ }^{5-16}$. In this study, the effect of RVR on composite microstructure and thermal properties were examined in 5\%,10\% and 15\% $\mathrm{MgO}$ reinforced composites produced by melt stirring method.

There are various studies investigating the effects of RVR on mechanical and thermal properties in composites ${ }^{17,18}$. Thermal conductivity of composite materials has recently emerged as an important research topic. Several techniques have been developed recently for conductivity measurements. The flash technique has been widely used for determining thermal properties at wide ranges of temperatures ${ }^{19,20}$. In this technique, which is also employed in this study, the front surface of a small sample is subjected to a very short burst of high intensity radiant energy. Numerical techniques have also been used in literature which calculates these properties $^{21-23}$, but the main change of principle in the numerical analysis carried out in this study is the use of real Scanning Electron Microscope (SEM) images

Microstructure has also significant importance on thermal conductivity behavior. Thermal conductivity can be kept under control by means of microstructural modification ${ }^{24,25}$. This can be performed by modeling 
studies using real microstructure images. However, for the application of Finite Element (FE), the individual intrinsic thermal conductivity values of the phases $\left(\mathrm{k}_{\mathrm{e}}\right.$ :effective thermal conductivity) need to be calculated. In this study, finite element method is used to investigate the effect of RVR on thermal conductivity in $\mathrm{Al}-\mathrm{MgO}$ composites produced by melt stirring.

\section{Experimental Study}

Commercially pure aluminum alloy (EN AW 1050A) and Magnesia $(\mathrm{MgO})$ with particle size of $-105 \mu \mathrm{m}$ were used respectively as liquid matrix and reinforcement elements in the production of composite specimens. The chemical compositions of matrix material $\mathrm{Al}$ and reinforcement element $\mathrm{MgO}$ are given in Table 1.

For the production of composite specimens; matrix material Al was put in the crucible in Figure 1, melting process was started and continued until the temperature of liquid matrix increased to $750{ }^{\circ} \mathrm{C}$. Stirring apparatus was immersed in liquid metal and stirring was started. Stirring speed was gradually increased until $500 \mathrm{rev} / \mathrm{min}$ and $\mathrm{MgO}$ powder determined on the basis of RVR was added in liquid metal by a funnel during stirring process. After the addition of reinforcement element $\mathrm{MgO}$ in liquid matrix $\mathrm{Al}$, the mixture was stirred about 4 minutes at $500 \mathrm{rev} / \mathrm{min}$ in order to allow homogenous distribution of $\mathrm{MgO}$ particles in the mixture. Subsequent to the completion of stirring, the crucible was taken out of the furnace, the liquid melt was poured in steel containers of $30 \mathrm{~mm}$ diameter was allowed to cool down at room temperature. Same processes were applied separately for each RVR.

Then, to examine microstructures and porosity of composite materials, SEM, EDS and optical microscope images were taken. Besides, porosity of the composites was determined by Buoyancy method which is based on Archimedes principle. Finally, the numerical model was set up by transforming the real SEM images. From these images, a thermal Ansys model was generated to determine effective thermal conductivity.

\section{Results and Discussion}

\subsection{Microstructure properties and the effect of $R V R$ on $\mathrm{MgO}$ particle distribution}

SEM images of composite specimens with $5 \% \mathrm{MgO}$, $10 \% \mathrm{MgO}$ and $15 \% \mathrm{MgO}$ RVR produced by melt-stirring are given in Figure 2.

The SEM images indicate that generally, increased RVR in the specimens result improved homogeneous distribution of $\mathrm{MgO}$ particles. The white particles in microstructure images are $\mathrm{MgO}$ reinforcement elements. It is seen that reinforcement element was not disributed homogeneously
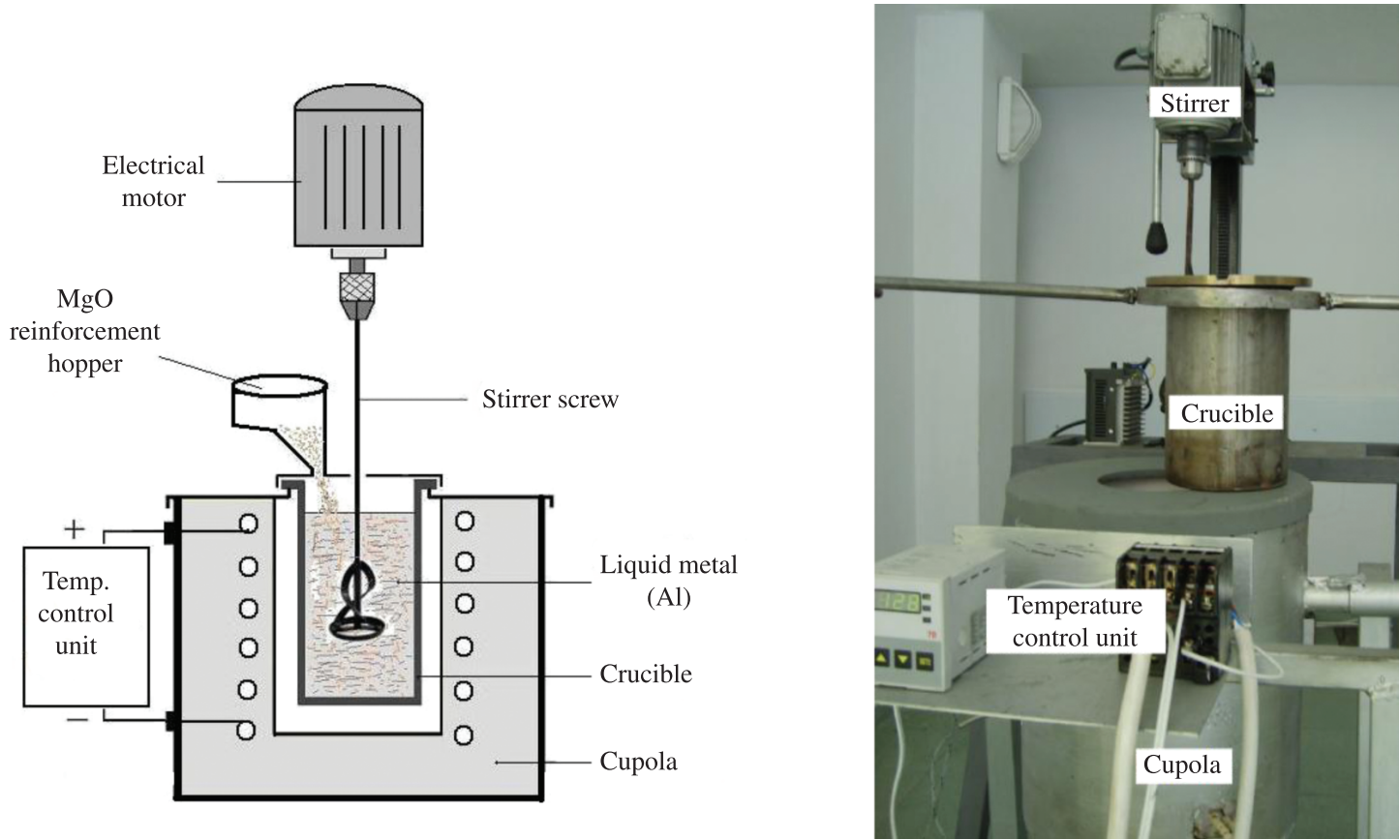

Figure 1. Melt stirring test apparatus (For the production of composite specimens).

Table 1. Chemical composition of matrix material $\mathrm{Al}$ and reinforcement element Magnesia.

\begin{tabular}{cccccccccc}
\hline EN AW 1050A & Al \% & Fe\% & Cu\% & Mn\% & Mg\% & Ti\% & Zn\% & Si \% & Remainder \\
\hline Magnesia & 99.5 & 0.40 & 0.05 & 0.05 & 0.05 & 0.05 & 0.07 & 0.25 & 0.03 \\
\hline & MgO $\%$ & & Fe\% & \multicolumn{3}{c}{ SiO2\% } & & CaO\% \\
\hline
\end{tabular}




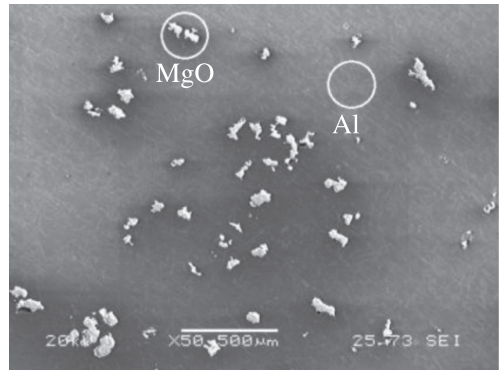

(a)

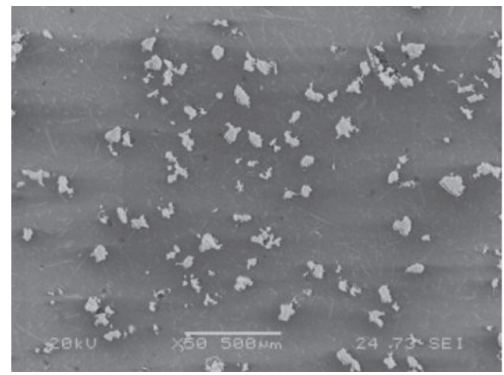

(b)

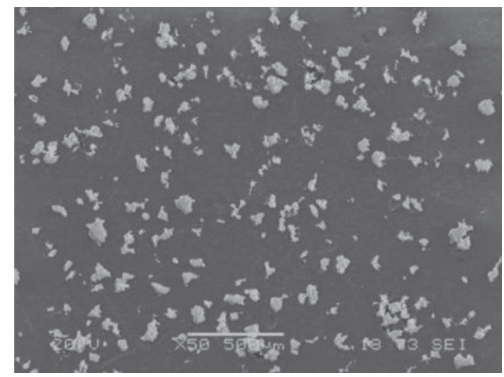

(c)

Figure 2. The microstructures of composite samples produced depending on the RVR of a) $5 \% \mathrm{MgO}$ b) $10 \% \mathrm{MgO}$ c) $15 \% \mathrm{MgO}$.

in $5 \% \mathrm{MgO}$ reinforced specimen (Figure 2a). This is possibly attributed to the partial agglomeration of the $\mathrm{MgO}$ particles and their exposure to sweeping during stirring in the low RVR. While the least homogeneous distribution of particles was recorded in 5\% $\mathrm{MgO}$ reinforced specimen; homogeneity further improved in $10 \% \mathrm{MgO}$ reinforced specimen (Figure $2 b$ ). and reached almost to that of the desired level in 15\% $\mathrm{MgO}$ reinforced specimen (Figure 2c).

According to results; the liquid $\mathrm{Al}$ temperature of $750{ }^{\circ} \mathrm{C}$ was suitable and stirring speed of $500 \mathrm{rev} / \mathrm{min}$ and stirring time of 4 minutes were sufficient. Besides, the addition of $\mathrm{MgO}$ with the particle size of $-105 \mu \mathrm{m}$ into the $\mathrm{Al}$ matrix by melt stirring method was suitable and the composite specimens can be produced successfully.

To examine the behaviour in every part of the mould and to determine the level of homogeneity of reinforcement distribution, one piece of $10 \% \mathrm{MgO}$ reinforced specimen was removed from the mould, polished with 1200 mesh emery paper and optical microscopic images from the top, central and bottom parts were taken. These images were given in Figure 3. Similar findings were also reported by Calın-Pul-Citak-Seker².

As seen from the images in Figure 3, the reinforcement element $\mathrm{MgO}$ was generally distributed homogeneously. However, a slight increase in the reinforcement ratio towards the bottom parts is observed in the images. This situation can be clarified by precipitation of reinforcement during the cooling of liquid mixture due to its higher specific gravity than that of the matrix material Al.

\subsection{The effect of RVR on the porosity structure}

According to theoretical and experimental calculations results, porosity value is $3.99 \%$ in $5 \% \mathrm{MgO}$ reinforced composite while porosity value is $4.16 \%$ in $10 \% \mathrm{MgO}$ reinforced composite. The most porous structures are seen on the $15 \% \mathrm{MgO}$ reinforced sample (4.42\%). These values were given in Figure 4.

This also supports increasing amount of porosity on the SEM images depending on the RVR (Figure 5). Similar results were specified by Calin-Pul-Citak-Seker².

EDS analyses were performed for the chemical identification of the reinforcement element $\mathrm{MgO}$ and matrix element $\mathrm{Al}$ in the composite specimens and the results of these analyses are given in Figures 6a and $b$.

When the microstructure in Figure 6 is examined, some amount of pores are seen in the composites which are formed
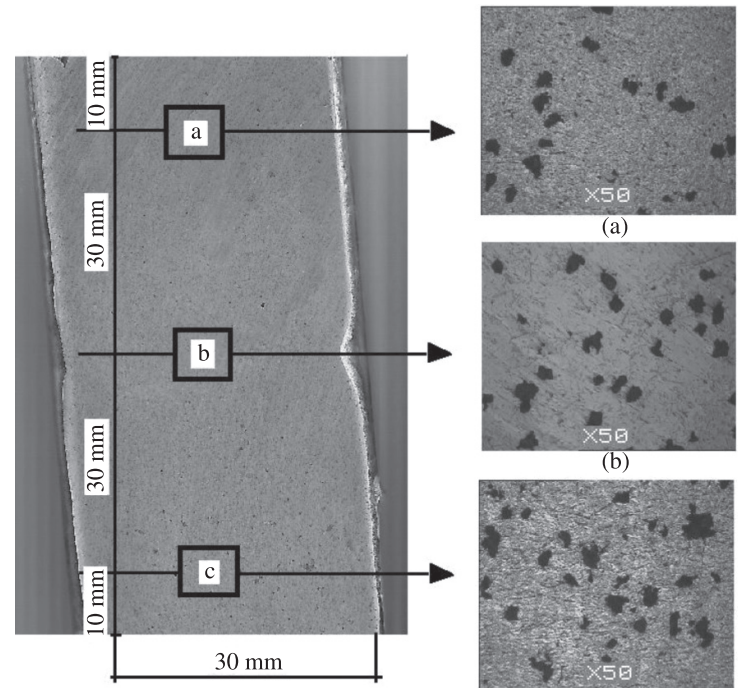

(b)

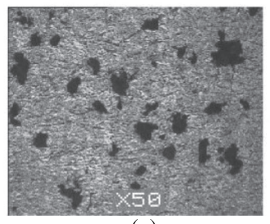

(c)

Figure 3. The regional microstructures of $10 \% \mathrm{MgO}$ reinforced sample a) Top b) Central c) Lower.

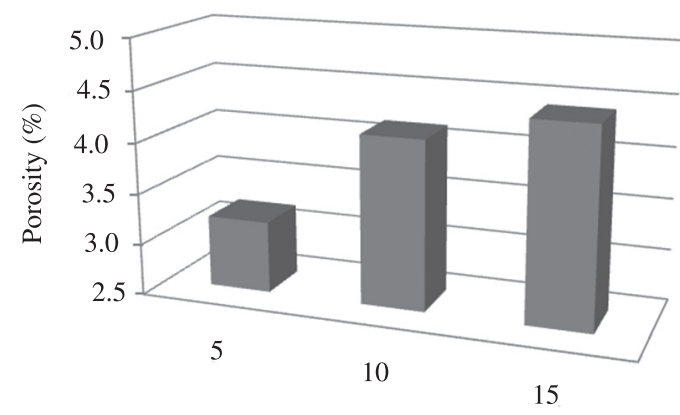

Volume fraction of reinforcement $\mathrm{MgO}(\%)$

Figure 4. RVR and porosity value relationship of composite samples.

at the matrix-reinforcement interface. The amount of pores can probably be decreased by increased stirring time. In the production of such MMCs, porosity can occur due to the difficulty in the wetting of the ceramic-based reinforcement elements by the matrix material Al. Similar findings were also reported by Calin-Citak, Acilar ${ }^{26,27}$. 


\subsection{The effect of $R V R$ on effective thermal conductivity}

A geometric model of the sample surface was developed for simulation of real micro structure images shown in Figures 2a-c. Images having different reinforcement volume ratios (RVR) were selected for the modeling study and were converted into a numerical model via a drawing tool for engineers (Mechanical Desktop). The reinforcement and matrix phases of boundaries were defined by conforming to the real image as much as possible to differentiate these two phases clearly. By the definition of the actual contacts, key points were identified for the transformation of the image to a numeric model. These key points were used to form the

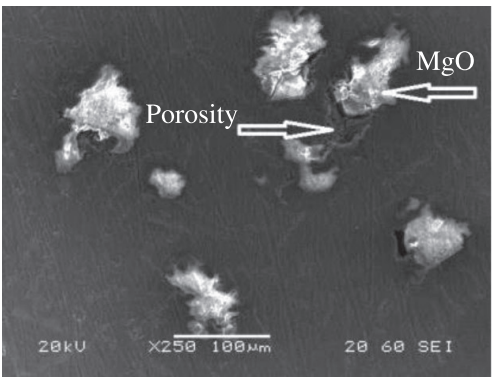

(a)

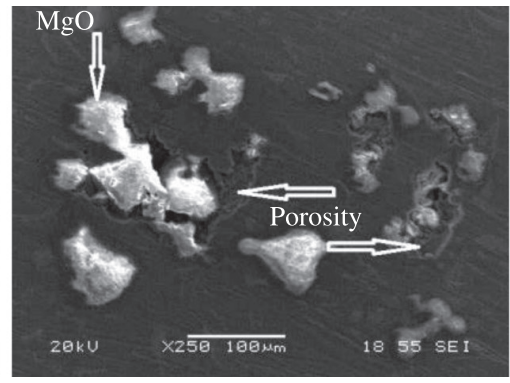

(b)

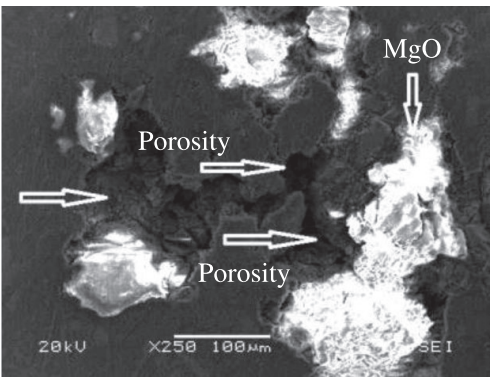

(c)

Figure 5. Porosities of composites which were produced depending on the RVR of a) $5 \% \mathrm{MgO}$ b) $10 \% \mathrm{MgO}$ c) $15 \% \mathrm{MgO}$.

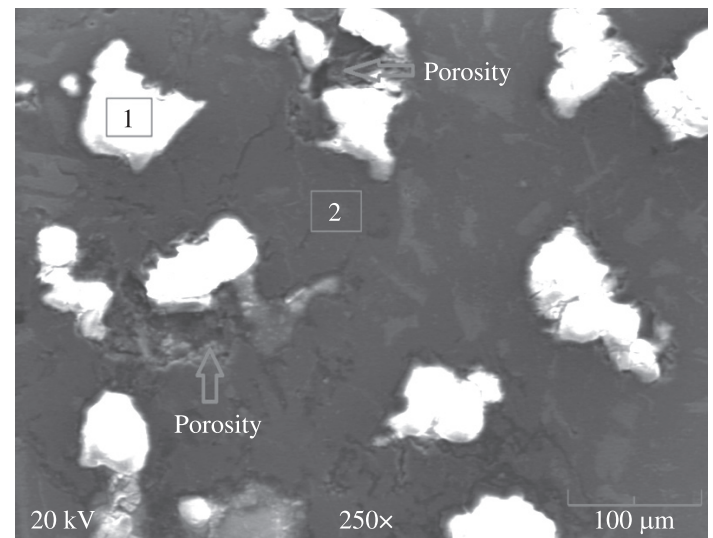

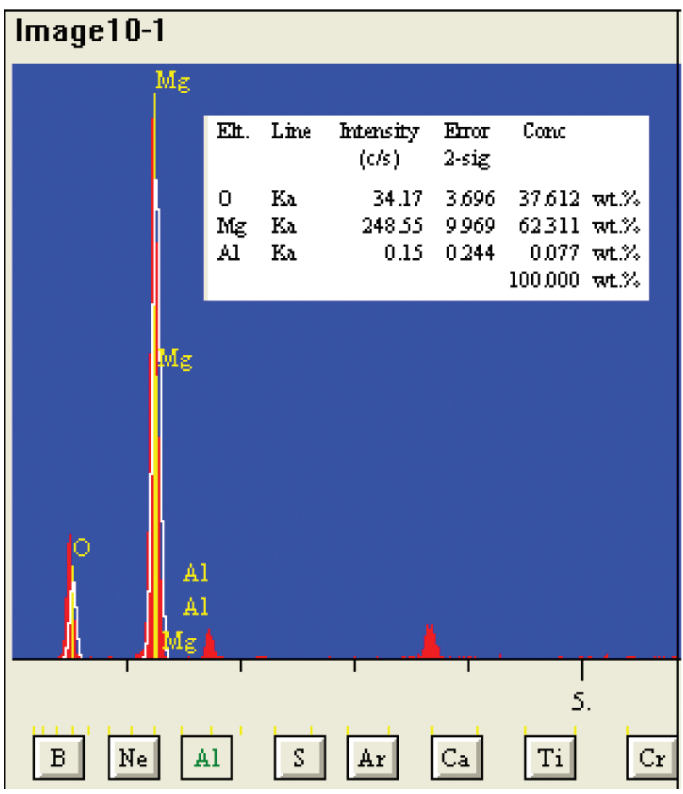

(a)

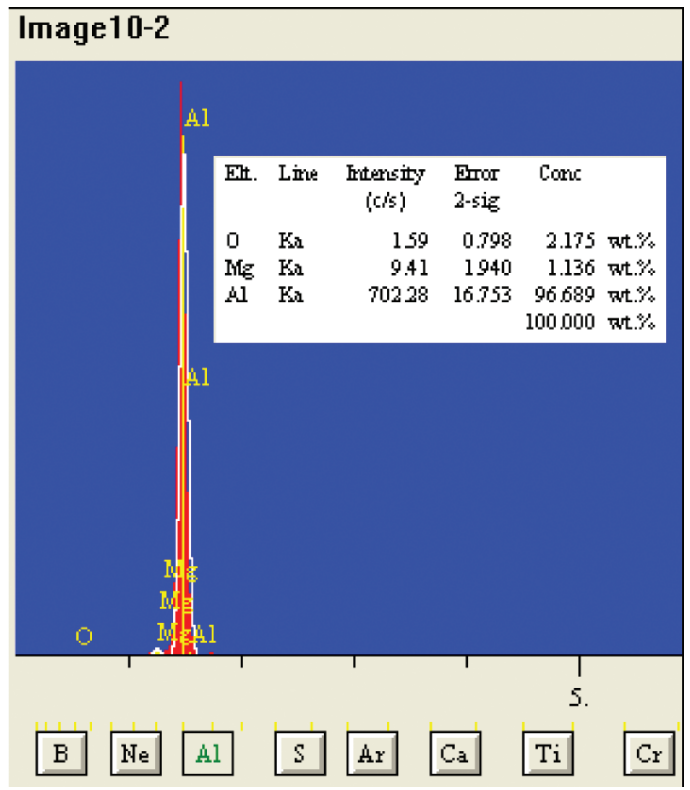

(b)

Figure 6. EDS Analyses of the composite taken from three different zones a) Analysis of Zone 1 b) Analysis of Zone 2. 
lines and the lines were used to form the areas. Consequently, the nodes were formed using the ANSYS (Finite Element Code). One by one reinforcement and matrix areas were meshed and the mesh form and the nodes, formed mesh later, in an enlarged image are shown in Figure 8a, 9a and 10a.

By the definition of the thermal conductivity of matrix and reinforcement phase, the problem was reduced to a heat transfer problem of a combined material, which is based on the heat transfer in a two-dimensional (2D) steady-state condition. Therefore, the solution was carried out under desired boundary conditions. In the solution, the Fourier heat transfer law (Equation 1) was applied in one direction, and a constant wall temperature and isolation surfaces was accepted as a boundary condition (see Figure 7)

$q x=-k \frac{d T}{d x}$

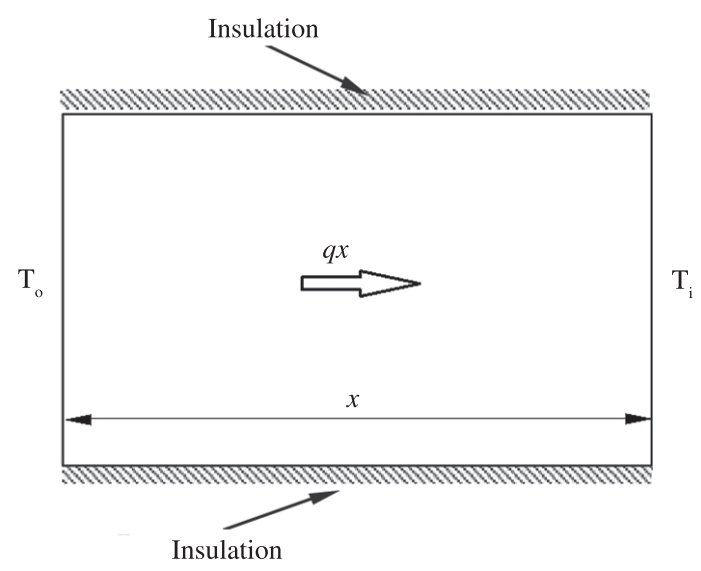

Figure 7. Thermal boundary conditions in Finite Element Model.

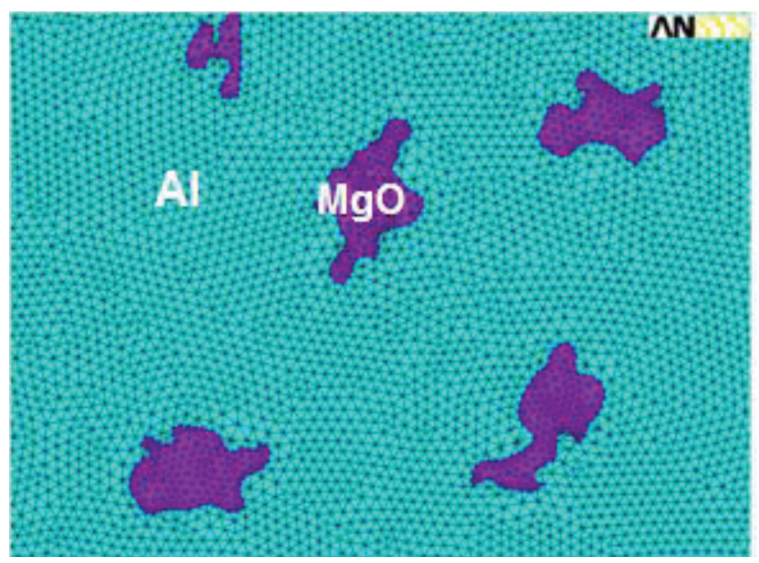

(a) where; $q_{x}$ is the total heat $(\mathrm{W}), \mathrm{T}_{\mathrm{i}}$ on the inlet surface temperature $(\mathrm{K}), \mathrm{T}_{\mathrm{o}}$ on the outlet surface temperature $(\mathrm{K})$, $k$ the thermal conductivity of material (W/m.K) and $x$ the distance of heat flow.

Then, effective thermal conductivity values of the composite materials were determined by Equation 1 with obtained from numeric results. Heat flux values $\left(q_{x}\right)$ have been obtained with help of numerical analysis and Equation 1. Effective thermal conductivity values of composite materials have been calculated by averaging and these values have been given Table 2 . Similar results have been obtained in literature 28,29 .

As the volumetric ratios used in the analytical models are determined from the digital images of the micrographs of composites, variations in the calculated thermal conductivities are observed depending on the RVR of composites.

The results, obtained from numerical analyses for different reinforcement ratios, showed how heat flow occurred in composite materials to addition it is given materials of effective thermal conductivity values. Finite element mesh of around of reinforcement materials as it can be seen from Figure 7a, 8a and 9a are created more intense according to matrix. The magnitudes of the thermal flux in an enlarged image examined numerically are shown in Figure 8b, 9b and 10b. When we investigate Figure $8 b, 9 b$ and $10 b$, it is clear that thermal flux is low in dark coloured part and it is high in light coloured part. Increased $\mathrm{MgO}$ reinforcement resulted decreased thermal conductivity of composites. The thermal resistance values at the ceramic particles are very high due to the very low thermal conductivity of reinforcement particle with respect to that of matrix. Depending on this, the magnitude of the thermal flux is greater in the Al matrix while it is much lower in $\mathrm{MgO}$ particles. This situation is directly related to the conductivity coefficients.

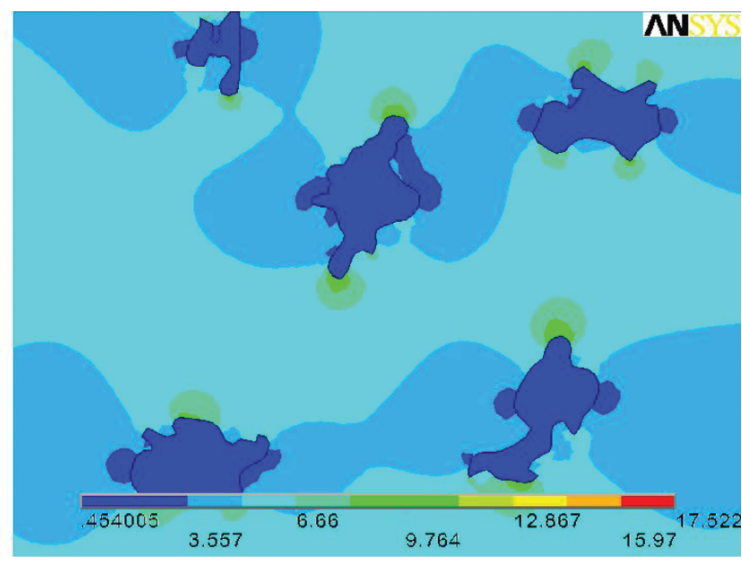

(b)

Figure 8. a) A piece of the transformed b) Enlarged vectoral illustration of numerical model in $5 \% \mathrm{MgO}$ thermal flux in $5 \% \mathrm{MgO}$.

Table 2. The effective thermal conductivity values obtained from numerical analysis from SEM images with different RVR.

\begin{tabular}{cccccc}
\hline Reinforcement volume ratio (\%) & Al & MgO & $\begin{array}{c}\text { Al + 5\% } \\
\text { MgO }\end{array}$ & Al + 10\% MgO & Al + 15\% MgO \\
\hline Effective thermal conductivity(W/m.K) & $210^{*}$ & $30^{*}$ & 194,92 & 178,35 & 141,99 \\
\hline
\end{tabular}

*The values are obtained from literature. 


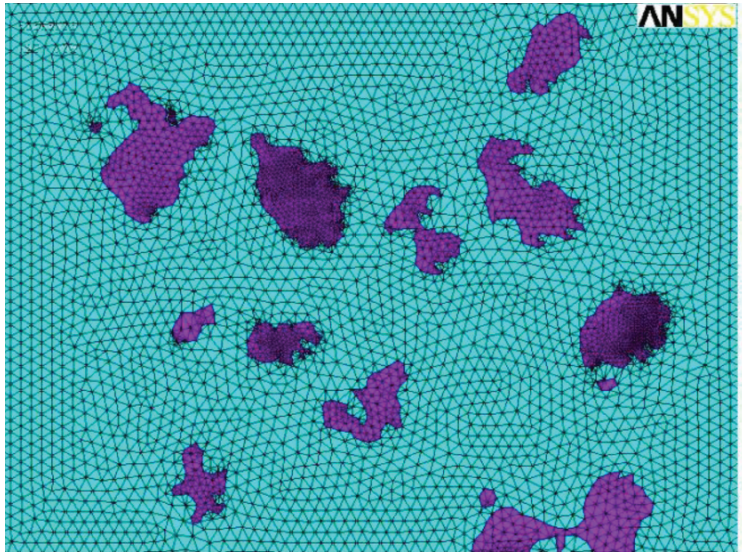

(a)

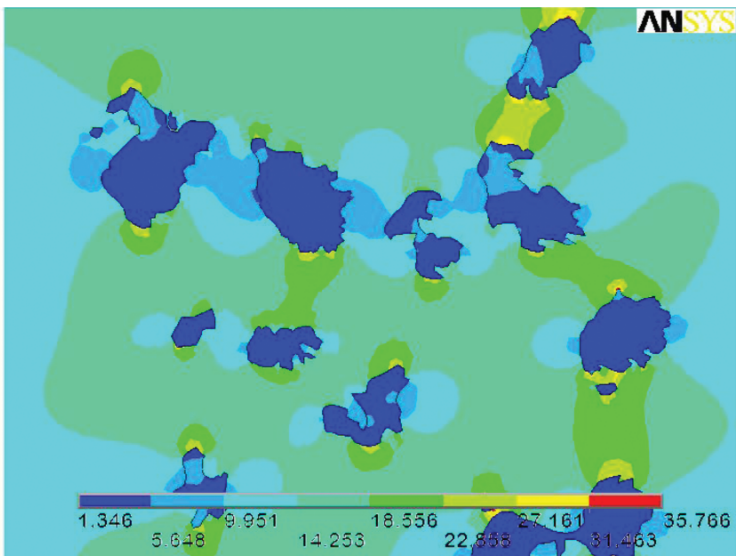

(b)

Figure 9. a) A piece of the transformed b) Enlarged vectoral illustration of numerical model in $10 \% \mathrm{MgO}$ thermal flux in $10 \% \mathrm{MgO}$.

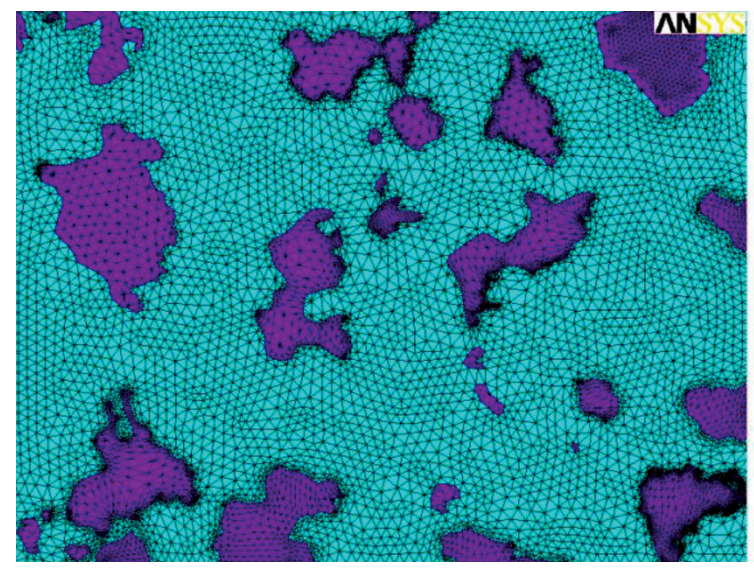

(a)

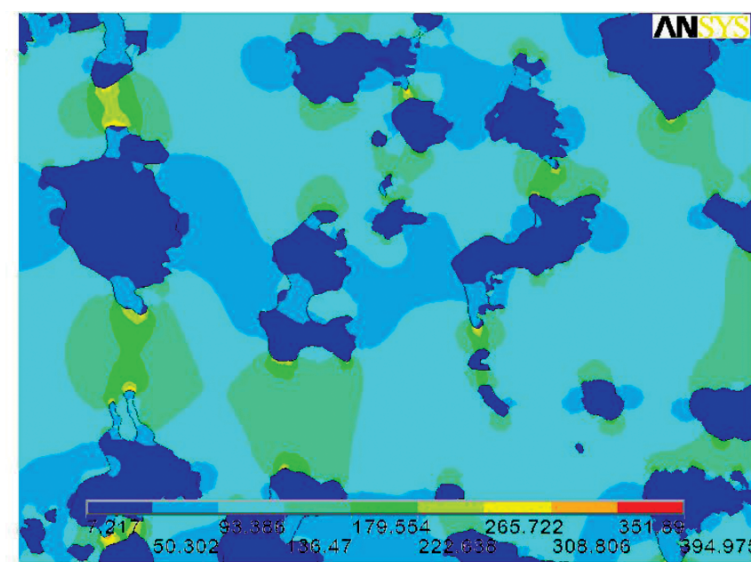

(b)

Figure 10. a) A piece of the transformed b) Enlarged vectoral illustration of numerical model in $15 \% \mathrm{MgO}$ thermal flux in $15 \% \mathrm{MgO}$.

\section{Conclusion}

The main results obtained from this study are summarized below:

In the MMCs production by the melt stirring method, the $\mathrm{MgO}$ with the particle size of $-105 \mu \mathrm{m}$ was homogeneously distributed inside the liquid $\mathrm{Al}$ at all RVR. In this case, the particle size of the composite used in the production of $\mathrm{MgO}$ can be said to be appropriate.

There is a little difficulty in wetting because of increasing the amount of $\mathrm{MgO}$ reinforcement in liquid matrix.

It can be stated that $750{ }^{\circ} \mathrm{C}$ liquid $\mathrm{Al}$ temperature, $500 \mathrm{rev} / \mathrm{min}$, the mixing speed and mixing time of 4 minutes were sufficient in experiments. However, to obtain more homogeneous distribution of reinforcement within the matrix $\mathrm{MgO}$ and to improve the wetting these values can be increased.

Depending on the increasing $\mathrm{MgO}$ reinforcement ratio, the porosities increased in the composites. Increasing the porosities in high volume reinforcement may be benefit to reducing the effective thermal conductivity of Al-MgO composites.

To say how much decrease porosity rate within composite structure, experiment parameters like the liquid Al temperature, stirring speed, stirring time are changed, In the RVR, wide range of experiments can be made and this may be evaluated as a separate study.

The effective thermal conductivity of Al-MgO composites increases while the RVR decreases. The magnitude of the thermal flux is greater in the $\mathrm{Al}$ matrix while it is much lower with respect to this value in $\mathrm{MgO}$ particles

\section{Acknowledgement}

The authors are grateful to Kirıkkale University for the support of this work with the project number of 2011/72. 


\section{References}

1. Sur G, Sahin Y and Gokkaya H. Production of aluminum based particulate reinforced composites using molten metal mixing and squeeze casting methods. Journal of the Faculty of Engineering and Architecture of Gazi University. 2005; 2:233-238.

2. Calin R, Pul M, Citak R and Seker U. The effect of reinforcement ratio on the composite structure and mechanical properties in $\mathrm{Al}-\mathrm{MgO}$ composites produced by the melt stirring method. Advanced Composites Letters. 2011; 20(4):91-96.

3. Sur G, Sahin Y and Gokkaya H. Production of Aluminum Based Particulate Reinforced Composites Using Molten Metal Mixing and Squeeze Casting Methods. Journal of the Faculty of Engineering and Architecture of Gazi University. 2005; 20(2):233-238.

4. Seo YH and Kang CG. The Effect of Applied Pressure on Particle-Dispersion Characteristics and Mechanical Properties in Melt-Stirring Squeeze-Cast SiCp/Al Composites. Journal of Materials Processing Technology. 1995; 55:370-379. http:// dx.doi.org/10.1016/0924-0136(95)02033-0

5. Hanumanth GS and Irons GA. Particle incorporation by melt stirring for the production of metal-matrix composites. Journal of Materials Science. 1993; 28:2459-2465. http://dx.doi org/10.1007/BF01151680

6. Hashim J, Looney L and Hashmi MSJ. Particle distribution in cast metal matrix composites-Part I. Journal of Materials Processing Technology. 2002; 123:251-257. http://dx.doi. org/10.1016/S0924-0136(02)00098-5

7. Tham LM, Gupta M and Cheng L. Influence of processing parameters during disintegrated melt deposition processing on near net shape synthesis of aluminium based metal matrix composites. Materials Science and Technology. 1999; 15:1139-1146.

8. Kok M. Production and mechanical properties of $\mathrm{Al}_{2} \mathrm{O}_{3}$ particle-reinforced 2024 aluminium alloy composites. Journal of Materials Processing Technology. 2005; 161:381-387. http:// dx.doi.org/10.1016/j.jmatprotec.2004.07.068

9. Luo A. Processing, microstructure, and mechanical behavior of cast magnesium metal matrix composites. Metallurgical and Materials Transactions A. 1995; 26:2445-2455.

10. Naher S, Brabazon D and Looney L. Development and assessment of a new quick quench stir caster design for the production of metal matrix composites. Journal of Materials Processing Technology. 2004; 166:430-439. http://dx.doi. org/10.1016/j.jmatprotec.2004.09.043

11. Ray S. Synthesis of cast metal matrix particulate composites. Journal of Materials Science. 1993; 28:5397-5413. http:// dx.doi.org/10.1007/BF00367809

12. Salvo L, L'Espérance G, Suéry M and Legoux JG. Interfacial reactions and age hardening in $\mathrm{Al}-\mathrm{Mg}$-Si metal matrix composites reinforced with $\mathrm{SiC}$ particles. Materials Science and Engineering: A. 1994; 177:173-183. http://dx.doi. org/10.1016/0921-5093(94)90489-8

13. Bindumadhavan PN, Chia TK, Chandrasekaran M, Wah HK, Lam LN and Prabhakar O. Effect of particle-porosity clusters on tribological behavior of cast aluminum alloy A356-SiC $\mathrm{p}_{\mathrm{p}}$ metal matrix composites. Materials Science and Engineering A. 2001; 315:217-226. http://dx.doi.org/10.1016/ S0921-5093(00)01989-4

14. Prabu SB, Karunamoorthy L, Kathiresan S and Mohan B. Influence of stirring speed and stirring time on distribution of particles in cast metal matrix composite. Journal of Materials Processing Technology. 2006; 171:268-273. http://dx.doi. org/10.1016/j.jmatprotec.2005.06.071
15. Pai BC, Ramani G, Pillai RM and Satyanarayana KG. Role of magnesium in cast aluminium alloy matrix composites. Journal of Materials Science. 1995; 30:1903-1911. http:// dx.doi.org/10.1007/BF00353012

16. Zhou W and Xu ZM. Casting of SiC Reinforced Metal Matrix Composites. Journal of Materials Processing Technology. 1997; 63:358-363. http://dx.doi.org/10.1016/ S0924-0136(96)02647-7

17. Assar AEM. Fabrication of matrix composite by infiltration process - Part 2: Experimental study. Journal of Materials Processing Technology. 1999; 86:152. http://dx.doi. org/10.1016/S0924-0136(98)00304-5

18. Calin R and Citak R. Effect of Mg Content of Matrix on Infiltration Height in Producing $\mathrm{MgO}$ Reinforced $\mathrm{Al}$ Matrix Composite by Vacuum Infiltration Method. Materials Science Forum. 2007; 546-549:611-614. http://dx.doi.org/10.4028/ www.scientific.net/MSF.546-549.611

19. Casto SL, Valvo EL and Micari F. Measurement of temperature distribution within tool in metal cutting. Experimental tests and numerical analysis. Journal of Mechanical Science and Technology. 1989; 20:35-46.

20. Liu Y-R, Liu J-J, Zhu B-L, Luo Z-B and Miao H-Z. The computer simulation of the temperature distribution on the surface of ceramic cutting tools. Wear, An International Journal on the Science and Technology of Friction, Lubrication and Wear. 1997; 210:39-44.

21. Yang R and Chen G. Thermal Conductivity Modeling of Periodic Two-Dimensional Nanocomposites. Physical Review B. 2004; 69:1-10. http://dx.doi.org/10.1103/ PhysRevB.69.195316

22. Watari K, Hirao K, Toriyama M and Ishizaki K. Effect of Grain Size on the Thermal Conductivity of $\mathrm{Si}_{3} \mathrm{~N}_{4}$. Journal of the American Ceramic Society. 1999; 82:777-779. http://dx.doi. org/10.1111/j.1151-2916.1999.tb01835.x

23. Hirao K, Watari K, Brito ME, Toriyama M and Kanzaki S. High Thermal Conductivity in Silicon Nitride with Anisotropic Microstructure. Journal of the American Ceramic Society. 1996; 79:2485-2488. http://dx.doi org/10.1111/j.1151-2916.1996.tb09002.x

24. Haggerty JS and Lightfoot A. Opportunities for Enhancing the Thermal Conductivities of $\mathrm{SiC}$ and $\mathrm{Si}_{3} \mathrm{~N}_{4}$ Ceramics through Improved Processing. Ceramic Engineering and Science Proceedings. 1995; 475-487. http://dx.doi org/10.1002/9780470314715.ch52

25. Watari K. High Thermal Conductivity Non-Oxide Ceramics. Journal of the Ceramic Society of Japan. 2001; 109:7-16. http:// dx.doi.org/10.2109/jcersj.109.S7

26. Calin R and Citak R. Effect of Powder size on infiltration height in producing $\mathrm{MgO}$ reinforced $\mathrm{Al}$ matrix composites by vacuum infiltration method. Materials science forum. 2007; 534-536:797-800. http://dx.doi.org/10.4028/ www.scientific.net/MSF.534-536.797

27. Acilar M and Gul F. Production and development of A1-10Si/ SiCp metal matrix composites by vacuum infiltration. Journal of Polytechnic. 2002; 4:21-27.

28. Calin R. Effect of Reinforced Volume Ratio on Thermal Conductivity of $\mathrm{SiO}_{2}$ Reinforced Al Matrix Composite Produced by Vacuum Infiltration Method. Asian Journal of Chemistry. 2010; 22(1):808-814.

29. Citak R, Calin R and Pehlivanli Z. Effect of Reinforcement Volume Ratio on Thermal Conductivity of MgO Reinforced Al Matrix Composite Produced by Vacuum Infiltration Method Asian Journal of Chemistry. 2010; 22(5):4054-4060. 